\title{
HCN Channels: From the Role in Chronic Cerebral Hypoperfusion-Induced Cognitive Impairments to a New Therapeutic Target for Vascular Dementia
}

\author{
Pan Luo and Lianjun Guo*
}

Department of Pharmacology, School of Basic Medicine, Huazhong University of Science and Technology, China

${ }^{*}$ Corresponding author: Lianjun Guo, Department of Pharmacology, School of Basic Medicine, Tongji Medical College, Huazhong University of Science and Technology, Wuhan 430030, China, Tel: +8602783691762; E-mail: ljguo@hust.edu.cn

Received date: July 04, 2015; Accepted date: August 12, 2015; Published date: August 17, 2015

Copyright: @2015 Luo P et al. This is an open-access article distributed under the terms of the Creative Commons Attribution License, which permits unrestricted use, distribution, and reproduction in any medium, provided the original author and source are credited.

\begin{abstract}
Hyperpolarization-activated cyclic nucleotide-gated channels are concentrated in cortical and hippocampal pyramidal cell dendrites, where they play an important role in determining synaptic integration and plasticity phenomena. These channels have been suggested to be involved in physiological processes such as cognition as well as pathophysiological states such as epilepsy, pain, Parkinson's disease (PD) and Alzheimer's disease (AD). Recent evidences from our own researches have suggested that the learning and memory impairments caused by chronic cerebral hypoperfusion $(\mathrm{CCH})$ are associated with a change of $\mathrm{HCN} 1 / \mathrm{HCN} 2$ expression; therefore these channels may also be therapeutic targets for treatment of vascular dementia.
\end{abstract}

Keywords: Vascular dementia; HCN channels; Chronic cerebral hypoperfusion

\section{Review}

Vascular dementia $(\mathrm{VaD})$ is the second leading form of dementia after Alzheimer's disease (AD) among western countries [1]. It is a progressive disease caused by cerebrovascular diseases with the pathologic features of reduced blood flow in the brain that affects cognitive abilities [2-4]. Accordingly, the cognitive impairment associated with vessel disorders is an increasingly important and recognised area of the medicine of $\mathrm{VaD}$ patients. $\mathrm{CCH}$ is a common consequence of various cerebral vascular disorders and hemodynamic changes that contributes to the risk of $\mathrm{VaD}$. In rodents, the bilateral common carotid artery occlusion (2VO) model is so far the most effective and frequently-used experimental model to evaluate the relation between chronic cerebral hypoperfusion and vascular diseaserelated dementia [2,5-7]. However, the progress on understanding the basis of the disease and developing treatments is not encouraging. There are no drugs licensed for the treatment of $\mathrm{VaD}$. In this context, we reviewed the discoveries from our own research based on $2 \mathrm{VO}$ model that the role of $\mathrm{HCN}$ channels in $\mathrm{CCH}$-induced cognitive impairments and hypothesise a new therapeutic target toward developing novel treatments for dementia of vascular origin.

HCN channels are cation channels that open at membrane voltages close to resting membrane potentials and are directly regulated by the binding of cAMP. It was identified in the late 1970s in sinoatrial node cells and neurons [8-11]. The HCN channel family is comprised of four subtypes (HCN1-4). The predominant forms in the hippocampus and cortex are HCN1 and HCN2 [12,13]. In pyramidal and neocortical neurons, they show a large gradient of expression that can be 60 -fold increase from somatic to distal apical dendritic membranes [14]. The channels are formed by heteromeric or homomeric complexes and carry the hyperpolarization-activated current, Ih. In neuronal dendrites, Ih is proposed to be responsible for several important cellular functions and plays a fundamental role in controlling cellular excitability, rhythmic activity, dendritic integration, synaptic transmission, and plasticity phenomena [15-17] that participates in the pathogenic mechanism of certain neurological diseases in humans such as epilepsy [18-20], pain [21], PD [22,23], and $\mathrm{AD}$ [24]. As expected from the established role of HCN channels in neurons, they may also potentially be involved in the process of cognitive declines originated from vascular risks.

In fact, It has been [25] demonstrated that in cerebellar Purkinje cells, Ih stabilizes the integrative properties of Purkinje cells and ensures their input-output function. Using generalized and regional knockout mice, that deletion of the HCN1 channel causes a great reduction of $\mathrm{Ih}$ and the current in cells from HCN1-/- mice showed little dependence on voltage at potentials from $50 \mathrm{mV}$ to $70 \mathrm{mV}$. These changes alter the integrative properties of Purkinje cells and thereby impair motor learning and memory function. Further study from Nolan et al. [16] has showed that forebrain restricted deletion of HCN1 dramatically slows the activation and deactivation kinetics of Ih, thus modifying dendritic integration of CA1 pyramidal cells and resulting in enhanced LTP and spatial memory. What's more, Matt et al. [26] identified that oriens-lacunosum moleculare interneuron cells in slices from $\mathrm{HCN} 2-/$ - mice showed a alteration of Ih current, which reduced GABAergic output onto distal dendrites of CA1 pyramidal and caused an increased LTP in direct perforant pathway. While, data from Thuault et al. has showed that forebrain-restricted HCN1 channels deletion induces a substantial loss of $\mathrm{Ih}$, that altered the intrinsic persistent neural firing and impaired executive memory function [27]. And another study has further clarified the reduction of hippocampal HCN1 expression and Ih associates with a spatial learning deficit [28]. It seems that learning and memory are regulated by HCN channels/Ih currents that integrate synaptic information is well identified. On the other hand, a change of $\mathrm{HCN}$ channels can also be seen in response to cerebral ischemia [29]. Therefore, HCN channels as interesting targets may offer excellent opportunities for the development of novel drugs to treat cognitive deficits of vascular origin.

Our research from Li et al. [30] has described for the first time that the down regulation of $\mathrm{HCN} 1$ mRNA in the hippocampal CAl pyramidal neurons and neocortex under $\mathrm{CCH}$ condition is associated 
Citation: Luo P, Guo L (2015) HCN Channels: From the Role in Chronic Cerebral Hypoperfusion-Induced Cognitive Impairments to a New Therapeutic Target for Vascular Dementia. J Neurol Neurophysiol 6: 308. doi:10.4172/2155-9562.1000308

Page 2 of 6

with the spatial learning and memory impairments. These data opened new insights for further investigation of the physiological and pathological significances of $\mathrm{HCN} 1$ in vascular dementia and provided additional information for the characterization of HCN channels as a new prospective target for the medication of vascular dementia.

Further study from Li et al. [31] has identified that 5 weeks after induction of hypoperfusion, the reduction of HCN1 surface expression and increase in HCN2 surface expression in hippocampal CA1 may be implicated in the cognitive deterioration. In fact, properties of Ih are likely to be determined by diverse HCN subunits expression patterns across the cell membrane [32,33]. In hippocampal CA1 neurons, Ih are probably mediated by both heteromeric and homomeric HCN complexes [34] and HCN1 subunit is likely to interact with other HCN1 subunits to form homomeric channels due to the fact that amount of HCN1 protein is much higher than HCN2 [35]. When rats suffered from $\mathrm{CCH}$, the ratio of $\mathrm{HCN} 2 / \mathrm{HCN} 1$ surface expression in CA1 area was increased [31]. And this should increase the propensity of the $\mathrm{HCN} 2$ isoform's interaction with $\mathrm{HCN} 1$, which might augment $\mathrm{HCN} 1 / \mathrm{HCN} 2$ heteromerization and result in a higher contribution of heteromeric HCN channels to the macroscopic Ih accordingly [35]. Providing the homomeric HCN1 channels conduct fast-kinetic currents with modest cAMP gating and homomeric HCN2 channels conduct slower-kinetic Ih currents with robust cAMP-evoked shifts in voltage dependence [34,36-38], the properties of heteromeric HCN complexes should be differ from those of homomeric ones. Therefore, the increased ratio of surface $\mathrm{HCN} 2 / \mathrm{HCN} 1$ should significantly modify the properties of the macroscopic Ih in CAl pyramidal cells and contribute to pathological alteration of the hippocampal network, which may be responsible for cognitive impairments caused by $\mathrm{CCH}$ (A mechanistic explanation in Figure 1). These data have further clarified that surface expression of HCN subunits may be involved in the pathogenesis of vascular dementia and finding out an effective compound acting on surface $\mathrm{HCN} 1 / \mathrm{HCN} 2$ may be a promising therapy strategy for vascular dementia.

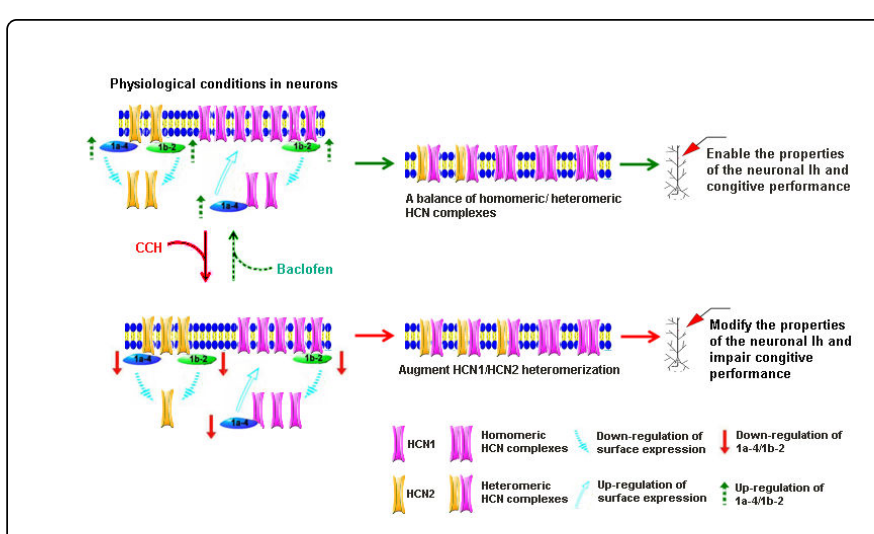

Figure 1: A mechanistic explanation for the change of $\mathrm{HCN}$ surface expression is implicated in the cognitive deterioration under $\mathrm{CCH}$ and baclofen ameliorates cognitive impairment via restoring the changed HCN surface expression. Hypoperfusion significantly reduced the protein levels of $1 \mathrm{a}-4$ and $1 \mathrm{~b}-2$, which lead to a reduction of $\mathrm{HCN} 1$ surface expression and increase in HCN2 surface expression. The ratio of $\mathrm{HCN} 2 / \mathrm{HCN} 1$ surface expression was increased. And this should increase the propensity of the interaction of $\mathrm{HCN} 2$ isoform's with $\mathrm{HCN} 1$, which might augment $\mathrm{HCN} 1 / \mathrm{HCN} 2$ heteromerization and result in a higher contribution of heteromeric HCN channels to the macroscopic Ih accordingly. The altered Ih should contribute to pathological alteration of the hippocampal network and may be responsible for cognitive impairments caused by $\mathrm{CCH}$. Baclofen can increase the expression and enhance the function of $1 \mathrm{a}-4$ and $1 \mathrm{~b}-2$ in $\mathrm{CCH}$ rats that restores the decreased HCN1 surface expression and increased HCN2 surface expression, which ameliorates the cognitive impairment caused by $\mathrm{CCH}$.

The findings of Li et al. [31] have several profound implications. First, they indicated that the increased ratio of HCN2/HCN1 surface expression in CA1 modify the properties of Ih. It is the changed Ih eventually contribute to the cognitive impairments in rats with $\mathrm{CCH}$. Second, the changed Ih can result from the imbalance of $\mathrm{HCN} 2 / \mathrm{HCN} 1$ surface expression, not just a reduction of $\mathrm{HCN} 1$ and increase in HCN2. Last, the findings of $\mathrm{Li}$ et al. also revealed that baclofen, a GABAB receptor agonist, has neuroprotective effects against chronic cerebral hypoperfusion. Its efficacy possibly via not only increasing the expression of TRIP8b (1a-4) and TRIP8b (1b-2) but also regulating the function of TRTP8b, then restored the balance of HCN1/HCN2 surface expression and reversed the cognitive deficits induced by $\mathrm{CCH}$ (Figure 1). Thus, the compounds act on accessory/regulatory protein resulting in restoring the balance of $\mathrm{HCN} 1 / \mathrm{HCN} 2$ surface expression or directly/indirectly changing the Ih (activation or inhibition) may be promising and indispensable drugs for treatment of disease.

There are a set of proteins (such as MiRP1, Filamin A, TRIP8b, Caveolin 3, tamalin, Mint2, S-SCAM, Nedd4-2 and KCR1) that affect the correct function of $\mathrm{HCN}$ ion channels by interaction at different levels [8,39-47]. However, among which, only the TRIP8b's functional significances were well identified. Tetratricopeptide repeat-containing Rab8b interacting protein (TRIP8b), an accessory protein, that regulates the cell surface expression and dendritic localization of HCN channels in an isoform-dependent manner $[48,49]$. In the brain, more than ten isoforms of TRIP8b are expressed [50]. A quantitative realtime PCR analysis demonstrated that TRIP8b (1a-4) and TRIP8b (1a) 
Citation: Luo P, Guo L (2015) HCN Channels: From the Role in Chronic Cerebral Hypoperfusion-Induced Cognitive Impairments to a New Therapeutic Target for Vascular Dementia. J Neurol Neurophysiol 6: 308. doi:10.4172/2155-9562.1000308

Page 3 of 6

are the most abundant TRIP8b mRNA species in the brain, representing $30 \%-40 \%$ and $25 \%-30 \%$ of total TRIP8b mRNA, respectively. While TRIP8b (1b-2) expressed at somewhat lower levels, accounts for $10 \%-15 \%$ of total brain TRIP8b mRNA [51]. TRIP8b (1a-4) strongly increases HCN1 surface expression [51,52] and decreases the surface expression of HCN2 [53]. While TRIP8b (1b-2) has been reported to produce a potent downregulation in the surface expression of HCN1 and HCN2 [43]. Therefore, TRIP8b acts as a gatekeeper of neuronal $\mathrm{HCN}$ channel activity that provides one of the most promising therapeutic targets for treating $\mathrm{VaD}$.

In addition to auxiliary subunits, many intracellular molecules, including small molecules (e.g. cAMP, PIP2, protons) and protein kinases (e.g. Src, p38-MAPK, PKC, cGKII, Ca2+/CaMKII), that influence $\mathrm{HCN}$ channel gating, kinetics and surface expression [37,54,55]. In fact, selective serotonin reuptake inhibitor (SSRI) antidepressants, whose primary action is based on the inhibition of 5HT reuptake in the central nervous system, have been used with FDA approved drugs for dementia in AD. And they play a positive role in hindering the progression of the $\mathrm{AD}$ and improving patients' cognitive performance [56-59]. Providing the large overlap between $\mathrm{AD}$ and $\mathrm{VaD}$ in clinical symptomatology, pathophysiology and neurochemical mechanisms [60-63], an effective treatment for AD may also offer benefits as a symptomatic treatment in VaD. Although most of the effects of antidepressants have been ascribed to their functions of neurogenesis activity, neurotrophin modulation and reduction of proteotoxicity [64-67], it is possible that acting on HCN channels may also contribute to or be responsible for antidepressants' efficacy on dementia since there is an interaction between the serotonergic systems and HCN channels [68-70] and SSRI antidepressants inhibit 5$\mathrm{HT}$ reuptake that can regulate the properties and trafficking of $\mathrm{HCN}$ channels via a way of activating PLC-PKA and p38-MAPK signaling pathways (Figure 2) [54,71-73]. It is worth mentioning that we have recently observed that fluoxetine can ameliorate cognitive impairments induced by $\mathrm{CCH}$ via down-regulation of $\mathrm{HCN} 2$ surface expression in the hippocampal CA1 area in rats (The data have not been published) and data from others also have showed that SB202190, a p38-MAPK inhibitor, can significantly reduce neuronal apoptosis in the hippocampus and rescue spatial learning and memory deficits in a rat model of vascular dementia [74]. In additional, acetylcholinesterase inhibitors such as galantamine have a long-term safety and cognitive effects in the treatment of probable $\mathrm{VaD}$ or $\mathrm{AD}$ with cerebrovascular disease [75-78]. Because acetylcholine generally exerts an inhibitory effect on Ih via a cAMP signaling way [54], galantamine may have a high propensity to modulate $\mathrm{HCN}$ channels, which may also participate in the mechanisms of its efficacy. What's more, CaMKII increases channels surface expression through the interacting protein TRIP8b (1a-4) or reduces the HCN gene transcription via Neuronal Restrictive Silencing Factor (NRSF) in pathological conditions [54], this target may also provide interventions for the treatment of $\mathrm{VaD}$.

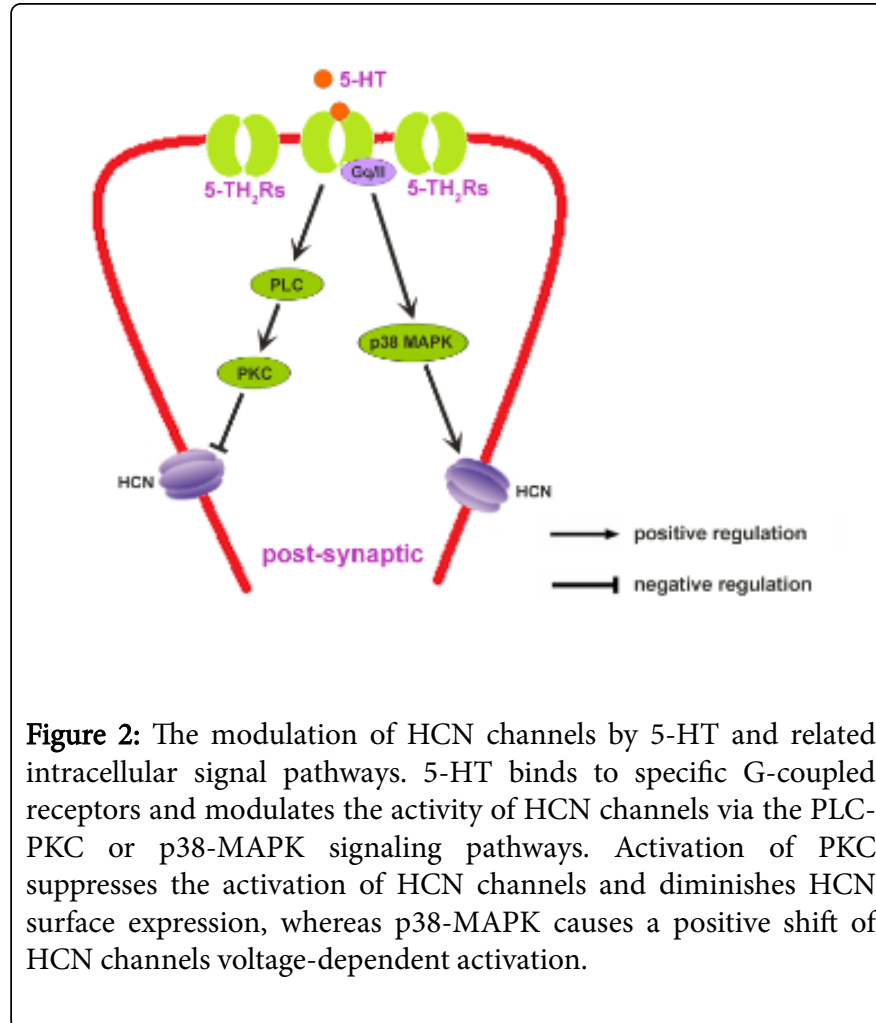

Furthermore, based on the fact that vascular dementia is a progressive disease, it seems that clarifying mechanisms of the disease process in a temporal manner is particularly important in terms of the intervention of disease. Luo et al. [79] have detected the dynamic change of $\mathrm{HCN} 1 / \mathrm{HCN} 2$ expression in CA1 at different stages of cognitive impairment caused by $\mathrm{CCH}$. Data have showed that the altered patterns of both $\mathrm{HCN} 1$ and HCN2 surface expression may be implicated in the early stage $(4 \mathrm{w})$ of spatial learning and memory impairments. Interestingly, the long-lasting cognitive impairments caused by $\mathrm{CCH}$ may partially attribute to the interference of $\mathrm{HCN} 2$ surface expression rather than HCN1. The increased surface expression of $\mathrm{HCN} 2$ subunits in the later stage of $\mathrm{CCH}(8 \mathrm{w}$ and $12 \mathrm{w})$ lead to an imbalance of $\mathrm{HCN} 2 / \mathrm{HCN} 1$ surface expression that could alters the hippocampal network as discussed above. What's more, the increased surface expression of HCN2 subunits may constrain the cognitive performance by elevating $\mathrm{Ih}$, since the increased Ih can lead to the decrease of input resistance and result in reduced synaptic summation. Therefore, HCN2 channels are more likely to be a novel therapeutic target for cognitive dysfunction in the progress of $\mathrm{VaD}$.

In the present, the treatment of $\mathrm{VaD}$ is limited to control vascular risk factors and there are no existing FDA approved treatment options for VaD. Thus, finding out effective treatments would be beneficial and imperative. The disorder of surface $\mathrm{HCN}$ subunits expression can cause cognitive defects under $\mathrm{CCH}$ condition, at least in rodents, that may be involved in the pathological process of $\mathrm{VaD}$. Therefore, the potential compounds act on surface HCN subunits, especially can down-regulate $\mathrm{HCN} 2$ surface expression in the progress of $\mathrm{VaD}$, would be a promising therapeutic strategy for the disease. What's more, compounds can regulate the accessory protein (such as TRIP8b) or protein kinases (such as PKC and p38-MAPK) may also have great potential to develop into effective drugs. However, there are also some crucial points should be considered. The subtype specificity has not yet 
been achieved in a satisfactory manner that the most important goal in the development of drugs targeting HCN channels will be the design of subtype-specific compounds probably. For the same reasons, it will be necessary to search for compounds that are selective for heteromeric/ homomeric channels. In additional, the compounds acting on intracellular molecules then regulate HCN channels requires a good penetration through the plasma membrane. And intracellular molecules affect the function of HCN ion channels may also have multiple biological effects to other effector proteins, which will generate adverse effects in treatment. Therefore, drug developing should avoid these inadequacies. The consideration of these points is likely to yield a better understanding of HCN channels' potential role as a promising target and perhaps result in better therapies.

\section{References}

1. Rizzi L, Rosset I, Roriz-Cruz M (2014) Global epidemiology of dementia: Alzheimer's and vascular types. Biomed Res Int 2014: 908915.

2. Venkat P, Chopp M, Chen J (2015) Models and mechanisms of vascular dementia. Exp Neurol .

3. Iadecola C (2013) The pathobiology of vascular dementia. Neuron 80 : 844-866.

4. Thal DR, Grinberg LT, Attems J (2012) Vascular dementia: different forms of vessel disorders contribute to the development of dementia in the elderly brain. Exp Gerontol 47: 816-824.

5. Bang J(2013) Biphasic functional regulation in hippocampus of rat with chronic cerebral hypoperfusion induced by permanent occlusion of bilateral common carotid artery. PLoS One 8: 70093.

6. Jiwa NS, Garrard P, Hainsworth AH (2010) Experimental models of vascular dementia and vascular cognitive impairment: a systematic review. J Neurochem 115: 814-828.

7. Soria G, Tudela R, Márquez-Martín A, Camón L, Batalle D, et al. (2013) The ins and outs of the BCCAo model for chronic hypoperfusion: a multimodal and longitudinal MRI approach. PLoS One 8: e74631.

8. Biel M, Wahl-Schott C, Michalakis S, Zong X (2009) Hyperpolarizationactivated cation channels: from genes to function. Physiol Rev 89: 847-885.

9. Brown HF, DiFrancesco D, Noble SJ (1979) How does adrenaline accelerate the heart? Nature 280: 235-236.

10. Halliwell JV, Adams PR (1982) Voltage-clamp analysis of muscarinic excitation in hippocampal neurons. Brain Res 250: 71-92.

11. Pape HC (1996) Queer current and pacemaker: the hyperpolarizationactivated cation current in neurons. Annu Rev Physiol 58: 299-327.

12. Bender RA (2001) Differential and age-dependent expression of hyperpolarization-activated, cyclic nucleotide-gated cation channel isoforms 1-4 suggests evolving roles in the developing rat hippocampus. Neuroscience 106: 689-698.

13. Monteggia LM, Eisch AJ, Tang MD, Kaczmarek LK, Nestler EJ (2000) Cloning and localization of the hyperpolarization-activated cyclic nucleotide-gated channel family in rat brain. Brain Res Mol Brain Res 81: 129-139.

14. Lörincz A, Notomi T, Tamás G, Shigemoto R, Nusser Z (2002) Polarized and compartment-dependent distribution of HCN1 in pyramidal cell dendrites. Nat Neurosci 5: 1185-1193.

15. Kase D, Imoto K (2012) The Role of HCN Channels on Membrane Excitability in the Nervous System. J Signal Transduct 2012: 619747.

16. Nolan MF, Malleret G, Dudman JT, Buhl DL, Santoro B, et al. (2004) A behavioral role for dendritic integration: HCN1 channels constrain spatial memory and plasticity at inputs to distal dendrites of CA1 pyramidal neurons. Cell 119: 719-732.

17. Park K, Yi JH, Kim H, Choi K, Kang SJ, et al. (2011) HCN channel activity-dependent modulation of inhibitory synaptic transmission in the rat basolateral amygdala. Biochem Biophys Res Commun 404: 952-957.
18. DiFrancesco JC, Barbuti A, Milanesi R, Coco S, Bucchi A, et al. (2011) Recessive loss-of-function mutation in the pacemaker HCN2 channel causing increased neuronal excitability in a patient with idiopathic generalized epilepsy. J Neurosci 31: 17327-17337.

19. Tang B, Sander T, Craven KB, Hempelmann A, Escayg A (2008) Mutation analysis of the hyperpolarization-activated cyclic nucleotide-gated channels HCN1 and HCN2 in idiopathic generalized epilepsy. Neurobiol Dis 29: $59-70$.

20. Nava C, Dalle C, Rastetter A, Striano P, de Kovel CG, et al. (2014) De novo mutations in HCN1 cause early infantile epileptic encephalopathy. Nat Genet 46: 640-645.

21. Jiang YQ, Sun Q, Tu HY, Wan Y (2008) Characteristics of HCN channels and their participation in neuropathic pain. Neurochem Res 33: 1979-1989.

22. Merrison-Hort R, Borisyuk R (2013) The emergence of two anti-phase oscillatory neural populations in a computational model of the Parkinsonian globus pallidus. Front Comput Neurosci 7: 173.

23. Chan CS, Glajch KE, Gertler TS, Guzman JN, Mercer JN, et al. (2011) HCN channelopathy in external globus pallidus neurons in models of Parkinson's disease. Nat Neurosci 14: 85-92.

24. Saito Y, Inoue T, Zhu G, Kimura N, Okada M, et al. (2012) Hyperpolarization-activated cyclic nucleotide gated channels: a potential molecular link between epileptic seizures and $\mathrm{AI}^{2}$ generation in Alzheimer's disease. Mol Neurodegener 7: 50.

25. Nolan MF, Malleret G, Lee KH, Gibbs E, Dudman JT, et al. (2003) The hyperpolarization-activated HCN1 channel is important for motor learning and neuronal integration by cerebellar Purkinje cells. Cell 115: 551-564.

26. Matt L, Michalakis S, Hofmann F, Hammelmann V, Ludwig A, et al. (2011) HCN2 channels in local inhibitory interneurons constrain LTP in the hippocampal direct perforant path. Cell Mol Life Sci 68: 125-137.

27. Thuault SJ, Malleret G, Constantinople CM, Nicholls R, Chen I, et al. (2013) Prefrontal cortex HCN1 channels enable intrinsic persistent neural firing and executive memory function. J Neurosci 33: 13583-13599.

28. Phillips AM, Kim T, Vargas E, Petrou S, Reid CA (2014) Spike-and-wave discharge mediated reduction in hippocampal HCN1 channel function associates with learning deficits in a genetic mouse model of epilepsy. Neurobiol Dis 64: 30-35.

29. Honsa P, Pivonkova H, Harantova L, Butenko O, Kriska J, et al. (2014) Increased expression of hyperpolarization-activated cyclic nucleotidegated $(\mathrm{HCN})$ channels in reactive astrocytes following ischemia. Glia 62: 2004-2021.

30. Li S, He Z, Guo L, Huang L, Wang J, et al. (2010) Behavioral alterations associated with a down regulation of HCN1 mRNA in hippocampal cornus ammon 1 region and neocortex after chronic incomplete global cerebral ischemia in rats. Neuroscience 165: 654-661.

31. Li CJ, Lu Y, Zhou M, Zong XG, Li C, et al. (2014) Activation of GABAB Receptors Ameliorates Cognitive Impairment via Restoring the Balance of HCN1/HCN2 Surface Expression in the Hippocampal CA1 Area in Rats With Chronic Cerebral Hypoperfusion. Mol Neurobiol 50: 704-720.

32. Chen S, Wang J, Siegelbaum SA (2001) Properties of hyperpolarizationactivated pacemaker current defined by coassembly of HCN1 and HCN2 subunits and basal modulation by cyclic nucleotide. J Gen Physiol 117: 491-504.

33. Abbas SY, Ying SW, Goldstein PA (2006) Compartmental distribution of hyperpolarization-activated cyclic-nucleotide-gated channel 2 and hyperpolarization-activated cyclic-nucleotide-gated channel 4 in thalamic reticular and thalamocortical relay neurons. Neuroscience 141: 1811-1825.

34. Santoro B, Chen S, Luthi A, Pavlidis P, Shumyatsky GP, et al. (2000) Molecular and functional heterogeneity of hyperpolarization-activated pacemaker channels in the mouse CNS. J Neurosci 20: 5264-5275.

35. Brewster AL, Bernard JA, Gall CM, Baram TZ (2005) Formation of heteromeric hyperpolarization-activated cyclic nucleotide-gated $(\mathrm{HCN})$ channels in the hippocampus is regulated by developmental seizures. Neurobiol Dis 19: 200-207. 
36. Robinson RB, Siegelbaum SA (2003) Hyperpolarization-activated cation currents: from molecules to physiological function. Annu Rev Physiol 65: 453-480.

37. Wahl-Schott C, Biel M (2009) HCN channels: structure, cellular regulation and physiological function. Cell Mol Life Sci 66: 470-494.

38. Brewster A, Bender RA, Chen Y, Dube C, Eghbal-Ahmadi M, et al. (2002) Developmental febrile seizures modulate hippocampal gene expression of hyperpolarization-activated channels in an isoform- and cell-specific manner. J Neurosci 22: 4591-4599.

39. Yu H, Wu J, Potapova I, Wymore RT, Holmes B, et al. (2001) MinKrelated peptide 1: A beta subunit for the $\mathrm{HCN}$ ion channel subunit family enhances expression and speeds activation. Circ Res 88: E84-87.

40. Gravante B, Barbuti A, Milanesi R, Zappi I, Viscomi C, et al. (2004) Interaction of the pacemaker channel HCN1 with filamin A. J Biol Chem 279: 43847-43853.

41. Wilkars W, Wollberg J, Mohr E, Han M, Chetkovich DM, et al. (2014) Nedd4-2 regulates surface expression and may affect $\mathrm{N}$-glycosylation of hyperpolarization-activated cyclic nucleotide-gated (HCN)-1 channels. FASEB J 28: 2177-2190.

42. Kimura K, Kitano J, Nakajima Y, Nakanishi S (2004) Hyperpolarizationactivated, cyclic nucleotide-gated HCN2 cation channel forms a protein assembly with multiple neuronal scaffold proteins in distinct modes of protein-protein interaction. Genes Cells 9: 631-640.

43. Santoro B, Wainger BJ, Siegelbaum SA (2004) Regulation of HCN channel surface expression by a novel C-terminal protein-protein interaction. J Neurosci 24: 10750-10762.

44. Braun AP (2009) Alternative splicing of TRIP8b diversifies its actions as an accessory subunit of neuronal HCN channels. Channels (Austin) 3: 217-218.

45. Barbuti A, Terragni B, Brioschi C, DiFrancesco D (2007) Localization of f-channels to caveolae mediates specific beta2-adrenergic receptor modulation of rate in sinoatrial myocytes. J Mol Cell Cardiol 42: 71-78.

46. Michels G, Er F, Khan IF, Endres-Becker J, Brandt MC, et al. (2008) K+ channel regulator KCR1 suppresses heart rhythm by modulating the pacemaker current If. PLoS One 3: e1511.

47. Noam Y, Ehrengruber MU, Koh A, Feyen P, Manders EM, et al. (2014) Filamin A promotes dynamin-dependent internalization of hyperpolarization-activated cyclic nucleotide-gated type 1 ( $\mathrm{HCN} 1)$ channels and restricts Ih in hippocampal neurons. J Biol Chem 289: 5889-5903.

48. Zerial M, McBride H (2001) Rab proteins as membrane organizers. Nat Rev Mol Cell Biol 2: 107-117.

49. DeBerg HA, Bankston JR, Rosenbaum JC, Brzovic PS, Zagotta WN, et al. (2015) Structural mechanism for the regulation of HCN ion channels by the accessory protein TRIP8b. Structure 23: 734-744.

50. Piskorowski R, Santoro B, Siegelbaum SA (2011) TRIP8b splice forms act in concert to regulate the localization and expression of HCN1 channels in CA1 pyramidal neurons. Neuron 70: 495-509.

51. Santoro B, Piskorowski RA, Pian P, Hu L, Liu H, et al. (2009) TRIP8b splice variants form a family of auxiliary subunits that regulate gating and trafficking of HCN channels in the brain. Neuron 62: 802-813.

52. Lewis AS, Schwartz E, Chan CS, Noam Y, Shin M, et al. (2009) Alternatively spliced isoforms of TRIP8b differentially control h channel trafficking and function. J Neurosci 29: 6250-6265.

53. Zolles G, Wenzel D, Bildl W, Schulte U, Hofmann A, et al. (2009) Association with the auxiliary subunit PEX5R/Trip8b controls responsiveness of HCN channels to cAMP and adrenergic stimulation. Neuron 62: 814-825

54. He C, Chen F, Li B, Hu Z (2014) Neurophysiology of HCN channels: from cellular functions to multiple regulations. Prog Neurobiol 112: 1-23.

55. Lewis AS, Estep CM, Chetkovich DM (2010) The fast and slow ups and downs of HCN channel regulation. Channels 4: 215-231.

56. Altman HJ, Stone WS, Ogren SO (1987) Evidence for a possible functional interaction between serotonergic and cholinergic mechanisms in memory retrieval. Behav Neural Biol 48: 49-62.
57. Schmitt JA, Wingen M, Ramaekers JG, Evers EA, Riedel WJ (2006) Serotonin and human cognitive performance. Curr Pharm Des 12 2473-2486.

58. Mowla A, Mosavinasab M, Haghshenas H, Borhani Haghighi A (2007) Does serotonin augmentation have any effect on cognition and activities of daily living in Alzheimer's dementia? A double-blind, placebocontrolled clinical trial. J Clin Psychopharmacol 27: 484-487.

59. Mowla A, Mosavinasab M, Pani A (2007) Does fluoxetine have any effect on the cognition of patients with mild cognitive impairment? A doubleblind, placebo-controlled, clinical trial. J Clin Psychopharmacol 27: 67-70.

60. Kalaria R (2002) Similarities between Alzheimer's disease and vascular dementia. J Neurol Sci 203-204: 29-34.

61. Fahlander K, Wahlin A, Almkvist O, Bäckman L (2002) Cognitive functioning in Alzheimer's disease and vascular dementia: further evidence for similar patterns of deficits. J Clin Exp Neuropsychol 24: 734-744.

62. Kalaria RN (2003) Comparison between Alzheimer's disease and vascular dementia: implications for treatment. Neurol Res 25: 661-664.

63. Laukka EJ, Jones S, Small BJ, Fratiglioni L, Bäckman L (2004) Similar patterns of cognitive deficits in the preclinical phases of vascular dementia and Alzheimer's disease. J Int Neuropsychol Soc 10: 382-391.

64. Chadwick W, Mitchell N, Caroll J, Zhou Y, Park SS, et al. (2011) Amitriptyline-mediated cognitive enhancement in aged $3 \times \mathrm{Tg}$ Alzheimer's disease mice is associated with neurogenesis and neurotrophic activity. PLoS One 6: e21660.

65. Aboukhatwa M, Luo Y (2011) Antidepressants modulate intracellular amyloid peptide species in N2a neuroblastoma cells. J Alzheimers Dis 24: 221-234.

66. Keowkase R, Aboukhatwa M, Luo Y (2010) Fluoxetine protects against amyloid-beta toxicity, in part via daf-16 mediated cell signaling pathway, in Caenorhabditis elegans. Neuropharmacology 59: 358-365.

67. Aboukhatwa M, Dosanjh L, Luo Y (2010) Antidepressants are a rational complementary therapy for the treatment of Alzheimer's disease. Mol Neurodegener 5: 10.

68. Hawkins VE, Hawryluk JM, Takakura AC, Tzingounis AV, Moreira TS, et al. (2015) HCN channels contribute to serotonergic modulation of ventral surface chemosensitive neurons and respiratory activity. J Neurophysiol 113: 1195-1205.

69. Santello M, Nevian T (2015) Dysfunction of cortical dendritic integration in neuropathic pain reversed by serotoninergic neuromodulation. Neuron 86: $233-246$.

70. Tang ZQ, Trussell LO (2015) Serotonergic regulation of excitability of principal cells of the dorsal cochlear nucleus. J Neurosci 35: 4540-4551.

71. Williams AD, Jung S, Poolos NP (2015). Protein kinase C bidirectionally modulates I and hyperpolarization-activated cyclic nucleotide-gated (HCN) channel surface expression in hippocampal pyramidal neurons. J Physiol 593: 2779-2792.

72. Reetz O, Strauss U (2013) Protein kinase C activation inhibits rat and human hyperpolarization activated cyclic nucleotide gated channel (HCN)1--mediated current in mammalian cells. Cell Physiol Biochem 31: 532-541.

73. Poolos NP, Bullis JB, Roth MK (2006) Modulation of h-channels in hippocampal pyramidal neurons by p38 mitogen-activated protein kinase. J Neurosci 26: 7995-8003.

74. Yang S, Zhou G, Liu H, Zhang B, Li J, et al. (2013) Protective effects of $\mathrm{p} 38$ MAPK inhibitor SB202190 against hippocampal apoptosis and spatial learning and memory deficits in a rat model of vascular dementia. Biomed Res Int 2013: 215798.

75. Bowler JV (2003) Acetylcholinesterase inhibitors for vascular dementia and Alzheimer's disease combined with cerebrovascular disease. Stroke 34: $584-586$

76. Corey-Bloom J (2003) Galantamine: a review of its use in Alzheimer's disease and vascular dementia. Int J Clin Pract 57: 219-223.

77. Small G, Erkinjuntti T, Kurz A, Lilienfeld S (2003) Galantamine in the treatment of cognitive decline in patients with vascular dementia or 
Citation: Luo P, Guo L (2015) HCN Channels: From the Role in Chronic Cerebral Hypoperfusion-Induced Cognitive Impairments to a New Therapeutic Target for Vascular Dementia. J Neurol Neurophysiol 6: 308. doi:10.4172/2155-9562.1000308

Page 6 of 6

Alzheimer's disease with cerebrovascular disease. CNS Drugs 17: 905-914.

78. Kurz AF, Erkinjuntti T, Small GW, Lilienfeld S, Damaraju CR (2003) Long-term safety and cognitive effects of galantamine in the treatment of probable vascular dementia or Alzheimer's disease with cerebrovascular disease. Eur J Neurol 10: 633-640.
79. Luo P, Lu Y, Li C, Zhou M, Chen C, et al. (2015) Long-lasting spatial learning and memory impairments caused by chronic cerebral hypoperfusion associate with a dynamic change of $\mathrm{HCN} 1 / \mathrm{HCN} 2$ expression in hippocampal CA1 region. Neurobiol Learn Mem 123: $72-83$. 